\title{
Prevalence of Post-traumatic Stress Disorder and Potentially Traumatic Events among Adolescents in Erbil City
}

\author{
Raveen Ismael Abdullah; Department of Nursing, College of Nursing, University of Duhok, Duhok , Iraq. \\ (Correspondence: raveenmayi@yahoo.com ) \\ Norhan Zeki Shaker; Department of Nursing, College of Nursing, Hawler Medical University, Erbil, Iraq.
}

\begin{abstract}
Background and Objectives: Many children and teenagers throughout lifetime maybe expose to extraordinary forms of stressful and traumatic events, particularly individuals who live in countries experiencing continuous conflicts such as Iraq. Approximately one-third of traumatized adolescents might develop symptoms of post-traumatic stress disorder. The current study aimed to evaluate the types of potentially traumatic events and prevalence of post-traumatic stress disorder among adolescents in Erbil city.

Methods: A descriptive cross-sectional study was carried out at eleven public and private schools in Erbil City. The samples of the study were selected in three stages; the schools' selection, the class selection in the schools, and involvement of 300 students within the study. Data were collected from face-to-face interview of participants from 1st of March to 15th May 2018. Screening for post-traumatic stress disorder was done by using the posttraumatic stress disorder screening tool. The validity and reliability have been verified. Frequency, percentage, mean, standard deviation, chi-square, t-tests, and Fisher exact test was used for data analysis.
\end{abstract}

Results: Majority of participants were Kurdish, from the host community; More than half of them were males and middle in the rank within their families while the most prevalent potentially traumatic events were identified to be emotional abuse and physical abuse. Such events include betrayal and disappointment, witnessing parents fighting with each other, witnessing direct physical torturing, and physical torture. Among traumatized adolescents it is predicted that about $41.7 \%$ have post-traumatic stress disorder.

Conclusions: Post-traumatic stress disorder is prevalent among adolescent students and it differs in terms of gender and type of schools. Post-traumatic stress disorder was found to be the highest percentage among females compared to males, and within public schools compared to private schools. The most prevalent potentially traumatic events among adolescents were emotional and physical trauma.

Key words: Adolescent, Child Maltreatment, Post-Traumatic Stress Disorders, Students, Schools.

Received: 7/12/2018

Accepted: 15/1/2019

Published: 30/5/2019

\section{INTRODUCTION}

Children and teenagers are vulnerable for experiencing many forms of stressful events due to the rapid physiological and psychological changes happening during adolescent years. This vulnerability can increase among adolescents living in countries facing crisis continuously. Trauma creates a loss of faith that there may be any safety in this world, and it smashes a person's innocence [1].. Wars, political and religious violence, forced displacement and migration, human right abuses, 
unemployment, and poverty have damaged Iraqi society, creating major public mental health crises [2]. .Post-Traumatic Stress Disorder (PTSD) can result from exposure to shocking trauma and is characterized by continual re-experiencing, avoidance/numbing, and hyper arousal, present for more than one month and associated with significant distress and/or functional impairment [3].. Trauma during the childhood period has been called as "the hidden epidemic" [1]. Many recover from traumatic events and others may develop symptoms of post-traumatic stress disorder [4], especially after exposure to a range of traumatic events [5], such as sexual and physical abuse, domestic and school violence, medical trauma, car accidents, war and terrorism, suicides, and other traumatic events [6]. Other individuals may develop PTSD after being exposed to Potentially Traumatic Events (PTEs) [7]. PTSD is a disabling disorder, in both the developed and the developing countries [8] which can lead to chronic psychiatric morbidity and loss of normal daily life [9]. It has a lifelong impact on multiple aspects of functioning, including adaptive and interpersonal functioning, emotion regulation, cognition and memory, and neuroendocrine function [4].The risk for PTSD among children relies upon on the nature of the trauma; the child's age and gender; and personal, family, and community factors [4]. Traumatic experiences may result from conflicts [10] as supported by literature that shows that the rate of PTSD among youth in Iraq has multiplied. Adolescents in Iraq have been exposed to different kinds of traumatic events during the last decade especially after the conflict of 2003[11], but the fact is even ordinary people who experience common stressful events may develop PTSD [12]. People in Iraq have been more or less continually exposed to war for more than three decades [13]. Iraq and the
Kurdistan region of Iraq have faced more difficulties and challenges since the influx of Syrian refugees which began in 2012 and Iraqi civil war against the Islamic State of Iraq and al-Sham (ISIS) in 2014 which resulted in thousands of internally displaced people [14]. This humanitarian crisis has created financial and political instabilities in the country [15]. Furthermore, the political violence as a factor for developing psychological distresses among community individuals has been taken in consideration [10]. It expected that adolescents in Kurdistan Region of Iraq along the ISIS war have been exposed to a variety of potentially traumatic events and violence such as physical violence, emotional violence, and domestic violence which resulted from different types of crisis and insecurities. Increase in the number of traumatic events result in increase in PTSD prevalence [16]. Therefore, it is important to identify teenager's psychological challenges for forming a more healthy generation of future adults. The current study aims to find the types of potentially traumatic events, prevalence of post-traumatic stress disorder and PTSD association with adolescent's sociodemographic characteristics in Erbil city.

\section{METHODS}

A descriptive cross-sectional study was carried out in a period from January to November 2018 among adolescent students in Erbil city. The study samples were recruited through multiple stage of random sampling from the list of 260 mixed schools which have grade level of six to eleven (basic, high, and secondary schools) in Erbil city of the Iraqi Kurdistan Region. Eleven schools were selected after dividing schools into two strata: private schools and public schools. Two private schools and nine public schools were randomly selected from each stratum using a 
proportionate stratified random sampling where the total number of private mixed schools were $45(17.3 \%)$ and the total number of public mixed schools were 215 $(82.6 \%)$ out of 260 schools. as researcher proportioned choosing sample fraction of $4 \%$ for both strata. The selected participants from the eleven schools (high, secondary, or basic schools) ranged from ages 11 to 17 years old (both sexes) from grades six to eleven. Using simple random sampling, 52 students were from private schools and 248 students were from public schools. Adolescent students from twelfth school grade level and those whose age less than 11 years or more than 17 years old were excluded from the study. Estimation of sample size in the current study was 303 adolescent students but unfortunately three of them have dropped out from the study. The study sample size has been calculated through using $n=Z 2 P(1-P) / d$ formula [17]. Prior to data collection ethical approval was obtained from Ethical Committee at the College of Nursing, Hawler Medical University, Erbil General Directorate of Education, and the consent of participated schools. Furthermore, the oral consent was taken from adolescent students for the participation in the study after confirmation of confidentiality, anonymity and participants self-determination by the researcher. Withdrawal from study was permitted whenever the person lost desire to answer questions or disclose. A reliable questionnaire format which consisted of three parts was used to collect data. The first part covered sociodemographic characteristics of adolescents such as school type, school grade level, age, gender, ordinal position in the family, nationality, type of residency, source of financial support, child labor. The second part assessed the potentially traumatic life events among adolescent students which included physical torture, threat to be tortured physically, witnessing parents fight with each other, being betrayed or disappointed, witness of physical torture, being affected by horror movies and indirect violence through television, experience of unexpected death of someone close, witnessing suicide or homicide and experience of car accidents. The last part of questionnaire has been adopted from the Primary Care of Post-Traumatic Stress Disorder screening tool (PC-PTSD-5) for screening probable PTSD. A score of three or more out of a total of five questions about how traumatic event(s) has affected him/ her over the past month is considered positive [18]. PC-PTSD-5 is based on the fifth edition of the Diagnostic and Statistical Manual of mental disorders (DSM5) which was published in the May 2013 [19]. Data collection has been done throughout face-to-face interview by researcher and it took place in an isolated room inside the school building to create a safe, supportive, and non-threatening environment for the participant. The validity of instruments has been verified for its accuracy, relevance, and clarity via a panel of experts. After conducting a pilot study on a sample of 30 adolescent students at one of the mixed basic schools the internal consistency and reliability was determined and measured via computation of Pearson product moment correlation and the $r$ value was $(r=0.8294)$. The collected data have been analyzed through using the statistical package for social science (SPSS, Version 23). The socio-demographic characters described by frequency, percentage, mean, and standard deviation tests. While chi-square, fisher exact test, and Independent t-tests used for identifying the significance of association. The $P$ value of $\leq$ less 0.05 used for determination of significance level. 


\section{RESULTS}

Tables 1 shows that the mean \pm SD of the participant's age was $14.02 \pm 1.62$, it also illustrates that the $92.7 \%$ of participants (278) were from the host community, 91.3\% were Kurds (274). 140 (46.7\%) were females and 160 (53.3\%) were males. The highest percentage, $76.7 \%$ of students were financially depended on their parents, and only $14.7 \%$ of adolescents were working for earning money. It also shows that $18.3 \%$ of adolescents who participated in the study were from grades eight and nine.

Table 1: Socio-demographic characteristics of adolescents.

\begin{tabular}{|c|c|c|}
\hline \multirow{2}{*}{ Characteristics } & \multicolumn{2}{|c|}{$n=300$} \\
\hline & $* \mathbf{F}$ & $* * \%$ \\
\hline \multicolumn{3}{|l|}{ Age } \\
\hline Mean \pm SD & & $14.02 \pm 1.62$ \\
\hline \multicolumn{3}{|l|}{ School grade level } \\
\hline Six & 52 & 17.3 \\
\hline Seventh & 54 & 18.0 \\
\hline Eighth & 57 & 19.0 \\
\hline Ninth & 28 & 9.3 \\
\hline Tenth & 53 & 17.7 \\
\hline Eleventh & & \\
\hline \multicolumn{3}{|l|}{ Gender } \\
\hline Female & 140 & 46.7 \\
\hline Male & 160 & 53.3 \\
\hline \multicolumn{3}{|l|}{ Ethnicity } \\
\hline Kurdish & 274 & 91.33 \\
\hline Arabic & 25 & 8.33 \\
\hline Turkmen & 1 & 0.33 \\
\hline \multicolumn{3}{|l|}{ Residency type } \\
\hline Host community & 278 & 92.7 \\
\hline Internally displaced person & 22 & 7.3 \\
\hline \multicolumn{3}{|l|}{ Financial support } \\
\hline Parents & 230 & 76.7 \\
\hline Siblings & 13 & 4.3 \\
\hline Financially independent & 44 & 14.7 \\
\hline $\begin{array}{l}\text { Others such as: grandfather, } \\
\text { uncle ,and other } 1^{\text {st }} \text { degree } \\
\text { relatives }\end{array}$ & 13 & 4.3 \\
\hline \multicolumn{3}{|l|}{ Working } \\
\hline Yes & 44 & 14.7 \\
\hline No & 256 & 85.3 \\
\hline
\end{tabular}

*F: frequency, $* * \%$ : percentage
Figure 1 shows that the highest percentage, $54.7 \%$ of participants were the middle children in their families.

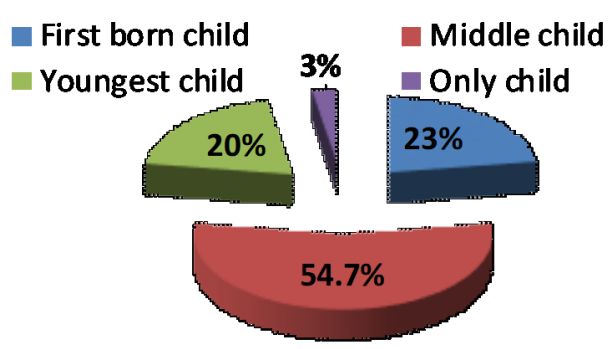

Figure 1: Ordinal position of adolescents in the family

Figure 2 shows that the prevalence of PTSD among adolescents was estimated to be $41.7 \%$ of whom probably had PTSD.

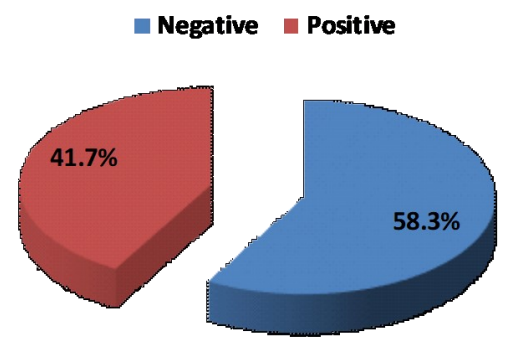

Figure 2: Prevalence of PTSD among adolescents' students in Erbil city

Table 2 illustrates the highest percentage, $56 \%$ of PTSD symptoms among adolescents was for "Tried hard not to think about the event(s) or went out of the way to avoid situations that reminded them of the event", and the least prevalent symptom, $27.7 \%$, was "Felt numb or detached from people, activities, or their surroundings". 
Table 2: Post-traumatic stress disorder symptoms among adolescents

\begin{tabular}{lcc}
\hline \multicolumn{1}{c}{ In the past month have you.. } & \multicolumn{1}{c}{$\mathbf{n = 3 0 0}$} \\
\cline { 2 - 3 } & Yes & No \\
\hline Had a nightmare about the event(s) or thought about event(s) when you & $\mathbf{F}(\%)$ & 201(67) \\
did not want to? & $99(33)$ & 132(44) \\
$\begin{array}{l}\text { Tried hard not to think about the event(s) or went out of your way to } \\
\text { avoid situations that reminded you of the event? }\end{array}$ & $168(56)$ & 162(54) \\
$\begin{array}{l}\text { Been constantly on guard, watchful, or easily startled? } \\
\text { Felt numb or detached from people, activities, or your surroundings? }\end{array}$ & 138(46) \\
$\begin{array}{l}\text { Felt guilty or unable to stop blaming yourself or others for the event(s) or } \\
\text { any problems the event(s) may have caused? }\end{array}$ & $122.3)$ \\
\hline
\end{tabular}

Table3 shows that most prevalent fighting with each other (53.3\%), and potentially traumatic events among witnessing physical torturing directly adolescents were: betrayal and dis- (46.3\%).

appointment $(58 \%)$, witnessing parents

Table 3: Prevalence of potentially traumatic events among study sample .

\begin{tabular}{|c|c|c|c|c|}
\hline \multirow{3}{*}{ PTEs } & \multicolumn{4}{|c|}{$\mathrm{n}=\mathbf{3 0 0}$} \\
\hline & \multicolumn{2}{|c|}{ NO } & \multicolumn{2}{|c|}{ YES } \\
\hline & $\mathbf{F}$ & $\%$ & $\mathbf{F}$ & $\%$ \\
\hline Physical torture & 173 & 57.7 & 127 & 42.3 \\
\hline Threatens to be tortured physically & 176 & 58.7 & 124 & 41.3 \\
\hline Witnessing parents fights with each other & 140 & 46.7 & 160 & 53.3 \\
\hline Being betrayed or disappointed & 126 & 42.0 & 174 & 58 \\
\hline Witness of physical torture & 161 & 53.7 & 139 & 46.3 \\
\hline Forced migration or displacement & 275 & 91.7 & 25 & 8.3 \\
\hline Experience car accident & 240 & 80.0 & 60 & 20 \\
\hline Long-term illnesses and hospitalizations & 271 & 90.3 & 29 & 9.7 \\
\hline Being affected by horror movies and indirect violence through TV & 212 & 70.7 & 88 & 29.3 \\
\hline Been in war zone & 257 & 85.7 & 43 & 14.3 \\
\hline Witnessing suicide or homicide & 274 & 91.3 & 26 & 8.7 \\
\hline Experience of unexpected death of someone close & 216 & 72.0 & 84 & 28 \\
\hline Witness of car accidents & 256 & 85.3 & 44 & 14.7 \\
\hline
\end{tabular}


According to Table 4 shows that, the mean age of those who had PTSD was 14 and there was no significant association found between PTSD and age,while a very highly significance in association between type of school and PTSD 119 (48\%) of participants from public schools and 6 (11.5\%) of participants from private schools have the likelihood of having PTSD. Results indicate there is a highly significant association between gender and PTSD ( $p$-value is less than 0.0001). PTSD prevalence among females $80(64 \%)$ is higher than in males 45 (36\%). The likelihood of having PTSD was 111 ( 88.8\%) among host community adolescents; 78 (62.4\%) among adolescents who receive their financial support from parents; 59 (47.2\%) among the middle children in families; and 93(74.4\%) among those adolescents who work for gaining their daily life income.

Table 4: Association between PTSD and socio-demographic characteristics of adolescent students'

\begin{tabular}{|c|c|c|c|}
\hline \multirow[b]{2}{*}{ Socio-demographic characteristics } & \multicolumn{3}{|l|}{ PTSD } \\
\hline & $\begin{array}{c}\text { Positive } \\
\text { F (\%) }\end{array}$ & $\begin{array}{c}\text { Negative } \\
\text { F (\%) }\end{array}$ & P-value \\
\hline \multicolumn{4}{|l|}{ Age } \\
\hline Mean士 SD & $14.13 \pm 1.598$ & $13.95 \pm 1.639$ & 0.498 \\
\hline Type of school & $6(11.5)$ & $46(88.5)$ & \\
\hline Private school & $119(48)$ & $129(52)$ & $<0.0001^{*}$ \\
\hline Public schools & & & VHS \\
\hline School grade level & $17(14.2)$ & $11(7.2)$ & \\
\hline Six & $20(16.7)$ & $34(22.2)$ & 0.341 \\
\hline Seventh & $22(18.3)$ & $33(21.6)$ & NS \\
\hline Eighth & $27(22.5)$ & $28(18.3)$ & \\
\hline Ninth & $13(10.8)$ & $15(9.8)$ & \\
\hline Tenth & $21(17.5)$ & $32(20.9)$ & \\
\hline \multicolumn{4}{|l|}{ Gender } \\
\hline $\begin{array}{l}\text { Female } \\
\text { Female }\end{array}$ & $80(64)$ & $60(34.3)$ & $<0.0001$ \\
\hline Male & $45(36)$ & $115(65.7)$ & VHS \\
\hline \multicolumn{4}{|l|}{ Ordinal position in family } \\
\hline First born child & $28(22.4)$ & $40(22.9)$ & \\
\hline Middle child & $59(47.2)$ & $105(60)$ & 0.028 \\
\hline Youngest child & $35(28)$ & $25(14.3)$ & $\mathrm{S}$ \\
\hline Only child & $3(2.4)$ & $5(2.9)$ & \\
\hline \multicolumn{4}{|l|}{ Residency type } \\
\hline Host community & $111(88.8)$ & $167(95.4)$ & 0.030 \\
\hline Internally displaced person & $14(11.2)$ & $8(4.6)$ & S \\
\hline \multicolumn{4}{|l|}{ financial support } \\
\hline Parents & $78(62.4)$ & $152(86.9)$ & $<0.0001$ \\
\hline Siblings & $10(8)$ & $3(1.7)$ & VHS \\
\hline Financially independent & $32(25.6)$ & $12(6.9)$ & \\
\hline Others & $5(4)$ & $8(4.6)$ & \\
\hline \multicolumn{4}{|l|}{ Working } \\
\hline Yes & $93(74.4)$ & $163(93.1)$ & $<0.0001$ \\
\hline No & $32(25.6)$ & $12(6.9)$ & VHS \\
\hline
\end{tabular}

*The chi-squared test was performed for all statistical analyses. NS: non-significant, VHS: very high significant, S: significant 


\section{DISCUSSION}

All human beings starting from childhood might go through many different shockable life events, and difficulties until reaching to adulthood. Exposure to such events might increase internal fears and create insecurities and if the impacts of traumatic events remain with person for long durations without support to cope with the aftermath of traumatic events, it may ultimately lead to psychological problems. The current descriptive crosssectional study which was carried out at eleven public and private schools in Erbil city and has demonstrated that the majority of adolescents in this study may have probable PTSD. The majority of adolescents expressed avoidance symptoms, and the least prevalent symptom was numbness and detachment from people, activities, or their surroundings. The current results were consistent to a 2017 study of 251 children from 3 summer camps ages 6 to 16 years in Palestine regarding PTSD symptoms which presented an intrusion mean of 8.98 and an avoidance symptoms subscale mean of 9.49 [20]. The results of another study prioritized social avoidance as one of the most common symptoms [21]. The current study also indicated that PTSD is prevalent and the results were very close to a study in Erbil during 2016 which showed the prevalence of PTSD among 570 participants aged between 15 and 64 years was $39.6 \%$ [22]. It's also consistent to PTSD prevalence of several other studies including studies in Mosul which suggested that, $37 \%$ of children have mental disorders, and $10.5 \%$ have PTSD; in Baghdad which revealed that, $47 \%$ of primary school children reported exposure to a major traumatic event, 14\% had PTSD [2] and the most potentially traumatic lifetime event among adolescents are betrayal/disappointment and witnessing parents fighting with each other. Exposure to child physical abuse and parents' domestic violence lead to PTSD [23]. It is difficult to sort out the research conducted on child maltreatment because various forms of maltreatment do not occur in isolation for example, physical maltreatment and emotional maltreatment often happened together [25]. Regarding sociodemographic characteristics and PTSD prevalence, a very significant association was found between type of school and gender. Almost half of participants from public schools present the likelihood of having PTSD, , In previous studies researchers have emphasized that adolescents attending private schools not only utilize more effective strategies to cope with problems, they also utilized emotionoriented strategies that were based on their relationships with others such as seeking out support from spiritual groups, talking with friends or identifying professional help [26]. Public schools adolescents are mostly from families with low economic status and from poor sectors of the community. Adolescent public school population size is relatively larger compared to private schools, thus creating a barrier for receiving adequate support and attention from school officials and family members. Children who have greater social support are less likely to develop PTSD than those without such support [25]. The highest percentages of those who have the likelihood of PTSD in current study were females. Findings from literature review supported the current study results which emphasized that girls are two to three times are likely to develop PTSD compared with boys [25], but the results disagreed with a study conducted in a sample of school children of 122 girls and 165 boys in Kabul, Afghanistan which found $26 \%$ prevalence of probable PTSD in boys compare to $14 \%$ in girls [28]. 
A significant association was found between PTSD and types of residency as the majority of those who have PTSD were from host community. This implies that despite of not being in war zone directly PTSD is prevalent among vulnerable groups silently [25]. Current study also concluded that almost half of those adolescents who receive money from parents they have PTSD and there is very highly significant association between PTSD and financial source. Those who work to earn money have a greater likelihood of having PTSD as environment of work for such age furthers the pressure on the adolescent population. This study also demonstrated that more than half of adolescents who receive their financial support from parents have likelihood of having PTSD. This may be a result of the recent economic crisis in Iraq which has created conflicts within families; no similar studies were found to support this. More than half of the adolescents who work for gaining their daily life income are likely to have PTSD which is supported from literature review findings that the there was a statistically significant association between PTSD and working during school and association between age and PTSD was also statistically significant. Almost half of the adolescents who are the middle child in current study probably have PTSD which is contrary with a finding of another study which revealed that $49.2 \%$ of the PTSD children were the first-born in their families [27].

\section{CONCLUSIONS}

The current study concluded that PTSD is prevalent among adolescent students in Erbil city despite of not going through war directly. Each of participants had a lifetime exposure to at least one of the types of potentially traumatic events assessed, and the most prevalent potentially traumatic events were emotional and physical trauma. Besides exposure and/or witness of traumatic events, there are many factors that interfere with probability of PTSD. It was concluded that there is an association with increased PTSD prevalence with factors such as the type of school, gender, ordinal position, residency type, source of financial support, and child labor.

\section{CONFLICTS OF INTEREST}

The authors have no conflict of interest.

\section{REFERENCES}

[1] Margolies L, read PD 3 min. Understanding the Effects of Trauma: Post-traumatic Stress Disorder (PTSD) [online]. Psych Central. 2016 .Available from: https:// psychcentral.com/lib/understanding-theeffects-of-trauma-post-traumatic-stressdisorder-ptsd/

[2] AlObaidi A. Psychological Trauma: Experience from Iraq. Journal of Trauma and Treatment. 2013 Nov 20;2(1):1-2.

[3] Suliman S, Kaminer D, Seedat S, Stein D. Assessing post-traumatic stress disorder in South African adolescents: using the child and adolescent trauma survey (CATS) as a screening tool. Annals of General Psychiatry. 2005 Jan 31;4(1):2.

[4] Gerson R, Rappaport N. Traumatic Stress and Posttraumatic Stress Disorder in Youth: Recent Research Findings on Clinical Impact, Assessment, and Treatment. Journal Adolescent Health. 2013 Feb 1;52(2):137-43.

[5] Calitz FJW, Jongh D, J N, Horn A, Nel ML, Joubert G. Children and adolescents treated for post-traumatic stress disorder at the Free State Psychiatric Complex. South African Journal of Psychiatry. 2014 Mar;20(1):15 -20 .

[6] American Psychological Association. Children and Trauma: Update for Mental Health Professionals [online]. http://www.apa.org. 2008 [cited 2018 Jul 26]. Available from: http://www.apa.org/pi/families/resources/ children-trauma-update.aspx 
[7] Cisler JM, Amstadter AB, Begle AM, Resnick HS, Danielson CK, Saunders BE, et al. PTSD Symptoms, Potentially Traumatic Event Exposure, and Binge Drinking: A Prospective Study with a National Sample of Adolescents.Journal of Anxiety Disorders. 2011 Oct; 25(7):978-87.

[8] Kaminer D, Seedat S, Stein DJ. Post-traumatic stress disorder in children. Official Journal of the world Psychiatric Association. 2005 Jun;4 (2):121-5.

[9] Mouthaan J, Sijbrandij M, Reitsma JB, Gersons BPR, Olff M. Comparing Screening Instruments to Predict Posttraumatic Stress Disorder. PLoS ONE [Internet]. 2014 May 9 [cited 2018 Jun 24];9(5). Available from: https://www.ncbi.nlm.nih.gov/pmc/articles/ PMC4016271/

[10] Ibrahim H, Hassan CQ. Post-traumatic Stress Disorder Symptoms Resulting from Torture and Other Traumatic Events among Syrian Kurdish Refugees in Kurdistan Region, Iraq. Frontier in Psychology. [Internet]. 2017 Feb 20 [cited 2018 Jul 28];8. Available from: https://www.ncbi.nlm.nih.gov/pmc/articles/ PMC5316552/

[11] Alshawi A. Posttraumatic Stress Disorder among Youth in Iraq, Short Systemic Review. Journal of Community Medicine and Health Care.2017 Feb 9;2(2).

[12] Kato N, Kawata M, Pitman RK, editors. PTSD: Brain Mechanisms and Clinical Implications. 2006 edition. Tokyo: Springer; 2006. 304 p.

[13] Al-Hadethe A, Hunt N, Thomas S, Al-Qaysi A. Prevalence of traumatic events and PTSD symptoms among secondary school students in Baghdad. European Journal of Psychotraumatology. 2014 Dec;5(1):23928.

[14] UN OCHA. Humanitarian Response Plan [Internet]. UN OCHA; 2017 [cited 2018 Jan 10]. Available from: https:// www.humanitarianresponse.info/en/ operations/iraq/document/2017-iraqhumanitarian-response-plan

[15] Rudaw. Poverty rate in Kurdistan Region quadrupled to 15 percent, official [Internet]. Rudaw. 2016 [cited 2018 May 27]. Available from: http://www.rudaw.net/english/ kurdistan/281220162

[16] Nils Womer. , Nils; Lamberty, IDP and Refugee Crises in the Kurdistan Region of Iraq.Lebanon: Konrad-Adenauer-Foundation (KAS) [Assessed on: 5th Feb, 2018]. 2016. Available from: http://www.kas.de/syrienirak/en/publications/47238/
[17] Lancaster CL, Teeters JB, Gros DF, Back SE. Posttraumatic Stress Disorder: Overview of Evidence-Based Assessment and Treatment. Journal of Clinical Medicine[Internet]. 2016 Nov 22 [cited 2018 Aug 28];5(11). Available from: https://www.ncbi.nlm.nih.gov/pmc/ articles/PMC5126802/

[18] Charan J, Biswas T. How to Calculate Sample Size for Different Study Designs in Medical Research? Indian Journal of Psychological Medicine. 2013;35(2):121-6.

[19] Prins A, Bovin MJ, Smolenski DJ, Marx BP, Kimerling R, Jenkins-Guarnieri MA, et al. The Primary Care PTSD Screen for DSM-5 (PCPTSD-5): Development and Evaluation Within a Veteran Primary Care Sample. Journal of General Internal Medicine. 2016 Oct 1;31 (10):1206-11.

[20] Regier DA, Kuhl EA, Kupfer DJ. The DSM-5: Classification and criteria changes. Official Journal of the world psychiatric Association. 2013 Jun;12(2):92.

[21] Thabet AM, Thabet SS. Stress, trauma and post-traumatic stress disorder among adolescents in the Gaza strip. Journal of trauma and critical care [Internet]. 2017 [cited 2018 Nov 5];1(2). Available from: http:// www.alliedacademies.org/abstract/stresstrauma-and-posttraumatic-stress-disorderamong-adolescents-in-the-gaza-strip8249.html

[22] Gökçen C, Sahingöz M, Annagür B. Does a non-destructive earthquake cause posttraumatic stress disorder? A cross-sectional study. European Child \& Adolescent Psychiatry. 2012 Nov 26;22.

[23] Karim B, Al-Salihy Z, Karim D, Laugharne R. Prevalence of Posttraumatic Stress Disorder in Erbil - Kurdistan .Arab Journal of Psychiatry. 2016 May;44(0):1-18.

[24] Margolin G, Vickerman KA. Post-traumatic Stress in Children and Adolescents Exposed to Family Violence: I. Overview and Issues. Professional Psychology Research and Practice. 2007 Dec 1;38(6):613-9.

[25] Mohr WK. Johnson's Psychiatric Mental Health Nursing: 5 edition. Lippincott Williams \& Wilkins; 2003. 832 p. 
[26] McLaughlin K. Posttraumatic stress disorder in children and adolescents: Epidemiology, pathogenesis, clinical manifestations, course, assessment, and diagnosis [Internet]. uptodate. 2018 [cited 2018 Nov 6]. Available from: https://www.uptodate.com/contents/ posttraumatic-stress-disorder-in-childrenand-adolescents-epidemiology-pathogenesis -clinical-manifestations-course-assessmentand-diagnosis\#H802051063

[27] Chavis S. Adolescents in Private Schools Cope Better [Internet]. 2010 [cited 2018 Nov 6]. Available from: https://psychcentral.com/ news/2010/10/30/adolescents-in-privateschools-cope-better/20174.html

[28] Lafta RK, Aziz ZS, AlObaidi A. Posttraumatic Stress Disorder (PTSD) among Male Adolescents in Baghdad. Journal of Psychological Abnormalities. 2014 Jun 14;3(3):1-5. 